\title{
Desalination using renewable energy sources on the arid islands of South Aegean Sea
}

\author{
Dimitrios Mentis ${ }^{\text {a, }}$, George Karalis ${ }^{b}$, Arthouros Zervos ${ }^{\text {b, c }}$, Mark Howells a, \\ Constantinos Taliotis a, Morgan Bazilian ${ }^{\mathrm{a}}$, Holger Rogner ${ }^{\mathrm{a}, \mathrm{d}}$ \\ a KTH Royal Institute of Technology, Stockholm, Sweden \\ ${ }^{\mathrm{b}}$ National Technical University of Athens, Greece \\ ${ }^{c}$ Public Power Corporation, Greece \\ ${ }^{\mathrm{d}}$ International Institute for Applied Systems Analysis, Laxenburg, Austria
}

\section{A R T I C L E I N F O}

\section{Article history:}

Received 27 March 2015

Received in revised form

27 October 2015

Accepted 1 November 2015

Available online $\mathrm{xxx}$

\section{Keywords:}

Desalination

Renewables

Islands

\begin{abstract}
A B S T R A C T
Water and energy supply are strongly interrelated and their efficient management is crucial for a sustainable future. Water and energy systems on several Greek islands face a number of pressing issues. Water supply is problematic as regards both to the water quality and quantity. There is significant lack of water on several islands and this is mainly dealt with tanker vessels which transport vast amounts of water from the mainland. At the same time island energy systems are congested and rely predominantly on fossil fuels, despite the abundant renewable energy potential. These issues may be addressed by combining desalination and renewable energy technologies. It is essential to analyse the feasibility of this possibility. This study focuses on developing a tool capable of designing and optimally sizing desalination and renewable energy units. Several parameters regarding an island's water demand and the desalination's energy requirements are taken into account as well as input data which concern technological performance, resource availability and economic data. The tool is applied on three islands in the South Aegean Sea, Patmos (large), Lipsoi (medium) and Thirasia (small). Results of the modelling exercise show that the water selling price ranges from $1.45 € / \mathrm{m}^{3}$ for the large island, while the corresponding value is about $2.6 € / \mathrm{m}^{3}$ for the small island, figures significantly lower than the current water cost (7 $-9 €\left(\mathrm{~m}^{3}\right)$.
\end{abstract}

() 2015 Elsevier Ltd. All rights reserved.

\section{Introduction}

The water scarcity on the Aegean islands is a long-standing problem. Recently this problem became more intense due to increasing population, tourism and the higher needs of the current living standards. The Hellenic State has chosen as a temporary solution to this issue the transportation of vast amounts of water with tanker vessels, which results in significant expenditures that burden the state [17]. At the same time, desalination technologies have matured and several units have been installed on the Greek islands [25]. Still, they are quite energy intensive. This adds to the already autonomous island energy systems that are facing overloads -inadequate generation problems arise on the basis of several black-outs especially during the summer [24]. Additionally the

\footnotetext{
* Corresponding author. Tel.: +46 760692060

E-mail address: mentis@kth.se (D. Mentis).
}

electricity generation is mainly comprised by diesel generators which run on imported fuel [11]. This paper considers the combination of desalination units running primarily on renewable energy sources, which are abundant on the Greek islands.

The main objectives of this paper are:

- To develop a tool to design and size coupled desalination and RET (renewable energy technology) units that will also provide investment indicators:

- To apply the tool on three island cases and compare the water production cost with the current costs.

- To quantitatively examine the impacts of a new legislative framework for combining RES (renewable energy source) and desalination functions;

Initially this paper describes the current water supply situation on the arid islands of South Aegean Sea. Section 1 then considers a proposal published by the Ministry of Infrastructure, Transport and 


\author{
Nomenclature \\ RET renewable energy technology \\ RES renewable energy source \\ HRES hybrid renewable energy system \\ RO reverse osmosis \\ PV photovoltaics \\ NPV net present value \\ PBP payback period \\ IRR internal rate of return
}

Networks in 2010 and the new RES (renewable energy source) legislation framework regarding desalination are analyzed Refs. [51,52]. Then, in Section 2 a methodology is presented for sizing desalination plants on the islands that will run on RET (renewable energy technology) plants which will supply part of the energy requirements of desalination. Moreover energy balances and cost of the system as well as selling prices that would make the investment viable for the Hellenic State and profitable for the investors are enumerated. This methodology is applied on three characteristic islands (large, medium, small) in Section 3 and several scenarios are constructed based on the legislation and the potential for RES penetration. Finally the results of this work are presented and compared with current water costs and conclusions are drawn regarding the feasibility of such a project.

\subsection{Previous assessments}

There is a plethora of studies and projects performed recently about the combination of desalination and renewable energy technologies.

A remarkable approach regarding the provision of renewable electricity and water supply on islands is introduced by Ref. [41]. An integrated RES system based on pumped storage and wind turbines is proposed for Ios Island (another arid island of South Aegean Sea). Generated electricity is used to cover energy requirements of the island as well as to meet the demand of a desalination unit, which will not only supply water to the island but also function as a supplementary unit for supplying the tanks with water when required.

The combination of desalination and renewable energy technologies is presented in a paper by Bennett [4] which demonstrates the importance of integrating these two technologies. Solar and wind energy are the major renewable energy technologies which are used to power desalination worldwide. They hold the lion's share with more than $80 \%$ of the corresponding generation [34]. However, biomass, hydro power, and ocean thermal energy are utilized to a lesser extent to generate electricity that feeds smaller desalination plants. Another substantial study is made by Eltawil et al. [13] in order to review the current methods of integrating the technologies, the corresponding costs and the potential environmental impact. They conclude that a combination of these systems is a technically mature option towards solving problems related to energy and water scarcity.

Voivontas et al. [48] demonstrate also a significant technoeconomic tool for the optimal selection of the most applicable RES and desalination technology. Several technical and economic parameters are taken into account and the users of the tool can vary these parameters according to the case study they are developing. The energy balances are being done on an annual basis.
Koroneos et al. [32] developed an integrated model for the use of wind and solar energy in the desalination of seawater, where they couple the two technologies to achieve the lowest system cost. Storage of the renewable electricity when necessary is implemented. Also in this direction by Hossam-Eldin et al. [20], investigate the use of hybrid renewable energy systems (HRES) in desalination using reverse osmosis (RO). In this case, unit production costs of both energy and desalinated water are compared for two existing small and medium RO plants powered with conventional electricity grid and electricity generated from the HRES. They conclude that hybrid systems remain an expensive source of power, which can be mainly used for remote power applications and are nowadays cost-effective, whereas extension of grid supply is expensive. Novosel et al. [38] have shown that a combined REdesalination configuration can increase the share of intermittent renewables in the production of electricity up to $76 \%$ resulting in a high reduction of fuel consumption.

The aforementioned sources as well as other useful "state of the art" studies in (Refs $[1,10,18,37]$ ) are used to develop a methodology on how to fulfil the objectives of this study. This study constitutes the first approach to develop a techno-economic tool capable of dimensioning and integrating renewable energy sources and desalination units to the grid and carry out an overall analysis and energy balance on an hourly basis throughout the year. There are several parameters taken into account that have not been considered in the previously stated studies; such are the legislation framework which allows a certain penetration of the renewables on the islands, solar irradiation, wind regime, land availability and others that are mentioned throughout the paper.

\subsection{Current situation}

While some water is supplied by private and municipal wells (primarily water of very low quality and high salinity) supplemented by rainwater collection (unreliable due to the intermittency of precipitation), the bulk is shipped to the islands by marine based water shipments at significant expense. The cost for the Hellenic Ministry of Shipping is significant, e.g., $7.3 € / \mathrm{m}^{3}$ for Dodecanese cluster of 26 islands and $9.3 € / \mathrm{m}^{3}$ for the Cyclades cluster of 33 islands [2], while the cost in Athens is less than $0.70 € \mid$ $\mathrm{m}^{3}$, which is the price of water for household consumption 5-20 $\mathrm{m}^{3}$ per month [14]. There are also several desalination units in operation which absorb vast amounts of energy in already overloaded island energy systems [28]. The desalination units are predominantly operated by municipalities which, due to shortages of a skilled workforce, face problems with their efficient and effective operation.

So what are the alternatives to water shipments from the mainland? Greek islands are endowed with abundant renewable energy resources [42] with the potential to meet existing and future energy demands. Renewable energy supply and desalination can be (and have been) combined/integrated. Their integration alleviates in large part the energy intensiveness of seawater desalination [43] and would burden already overload island energy systems. Furthermore, renewable supplies avoid greenhouse gas emissions since at least part, if not all, of the energy for desalination would be supplied by renewable sources.

\subsection{Practical implementation}

Greece is a pioneer country in the field of combining these two technologies. The University of the Aegean in cooperation with the Region of South Aegean developed the first wind powered floating desalination unit in the world, which provides electricity to the island of Iraklia on South Aegean Sea, covers the desalination 
Table 1

Comparison of main desalination technologies.

\begin{tabular}{|c|c|c|c|c|}
\hline Method & Production ( $\mathrm{m}^{3} /$ day) & Type of energy & Energy intensity $\left(\mathrm{kWh} / \mathrm{m}^{3}\right)$ & Installation cost $\left(€ / \mathrm{m}^{3} /\right.$ day $)$ \\
\hline Multiple stage flashing (MSF) & $1000-60,000$ & Heat/Electricity & $4-6$ & $1000-2000$ \\
\hline Multiple effect distillation (MED) & $500-20,000$ & Heat/Electricity & $2.5-3$ & $850-1750$ \\
\hline Vapor compression (VC) & $25-2500$ & Electricity & $8-15$ & $1000-2350$ \\
\hline Sea water reverse osmosis & $0.4-70,000$ & Electricity & $<5$ & $650-4400$ \\
\hline Brackish water reverse osmosis (BWRO) & $2.5-50,000$ & Electricity & $0.5-3$ & $300-2000$ \\
\hline Electrodialysis (ED) & $15-50000$ & Electricity & $1.5-4$ & $1000-5000$ \\
\hline
\end{tabular}

energy requirements and supplies electricity to the grid. The desalination unit's capacity reaches $70 \mathrm{~m}^{3}$ /day, which is enough to supply high quality water for approximately 300 people [44].

Another substantial project is undertaken on Milos, another island in South Aegean Sea with 150.6 sq. km area and more than 5000 inhabitants. There are three desalination units installed with total capacity of $3360 \mathrm{~m}^{3} /$ day which cover the entire water demand of the island. The electricity input to the desalination unit is supplied by a wind turbine with an installed capacity of $850 \mathrm{~kW}$ derated at $600 \mathrm{~kW}^{1}$ [7]. The trade-off between the electricity input to the desalination units and the electricity generated by the wind turbine is balanced on an annual basis.

\subsection{Desalination and renewable energy technology options}

There are two main techniques of desalinating water. Industrial desalination technologies use either membranes to separate the solvent and some solutes (membrane) or phase change (thermal). The membrane ones are single phase processes and utilize electricity for driving high pressure pumps. The most common technology in this category is Reverse Osmosis [8,15]. The thermal ones may be obtained from a conventional fossil-fuel source, nuclear energy or from a non-conventional solar energy source or geothermal energy [27]. Multiple stage flashing constitutes the most established thermal technology [30]. Multiple effect distillation, vapor compression and electrodialysis are some of the desalination technologies used nowadays [3].

A comparison is performed in terms of installation and O\&M costs, water quality, energy requirements and water production range and it is demonstrated in Table 1 and in Ref. [36]. The desalination method that has a prominent position on applications is reverse osmosis [16]. This technique presents a remarkable flexibility as it allows the construction of devices and systems in a great range in terms of water that can be produced per day; starting from the construction of the smallest device intended to meet the water needs of a family to the most extensive facility for water supply of a community or a town (Table 1 ).

Most of the Aegean Sea islands demonstrate high wind and solar potential $^{2}[31,49]$, and there is a well-established market of these two technologies [35]. Hence, these two technologies are chosen for further economic evaluation.

There are two possible ways of combining the two technologies, the fully autonomous systems and the systems connected to the grid. The first ones do not require connection to an electricity distribution network and are capable of generating the necessary electricity on their own. However, this combination leads to over dimensioning of the system due to the intermittency of RES and require energy storage and a complex design [33]. Also there is a siting and spacing problem since it is not always the case that both

\footnotetext{
${ }^{1}$ It is derated to $600 \mathrm{~kW}$ to reduce dumping of generated energy on the island.

2 The established solar power technology is solar photovoltaics in Greece. No CSP power plants have been introduced.
}

units can be placed spatially close to each other. As a result the water production cost is high [46].

On the other side, if both the RET and the desalination unit are connected to the grid there is a trade-off between the energy consumed by the desalination unit and the energy produced from the RET unit through a central remote monitoring system (SCADA) which coordinates all the functions of the subsystems [6]. This leads to higher renewable energy penetration and to lower water production cost. For this study, the second method of combining the two technologies proceeds in order to elaborate with and address the issues raised by the public consultation and the new RES legislation framework as mentioned hereinafter.

\subsection{Public consultation and new legislation framework RES/2010}

In response to the water supply situation, the Hellenic Ministry of Transportation published a proposal regarding the construction of desalination units on the Greek islands that are currently supplied by tanker vessels. The main points of the proposal are the following ones:

- A private sector investor and operator should undertake the construction and operation of each unit. The Hellenic State is supposed to subsidize the islands for covering their water cost needs.

- The Hellenic State suggests that wherever possible the desalination units should cover their energy requirements from Renewable Energy.

The new legislation framework for RES is also moving in this direction and states that the applications for RET installations combined with desalination unit installation are a top priority as long as the RET nominal capacity does not exceed $125 \%$ of the desalination unit's power capacity. The electricity from RET is balanced on an hourly basis with the electricity demanded by the desalination unit. The electricity surplus is supplied to the grid at a maximum $20 \%$ of the produced power on an hourly basis.

There are 3 different ways one can interpret the law-or in other words there are certain legislative margins, that can be evaluated through different lenses:

\section{Priority to desalination}

First a part or all the electricity requirements of the desalination unit are covered. The renewable energy surplus can be supplied to the grid at maximum $20 \%$ of the electricity output on an hourly basis.

\section{Priority to selling $20 \%$ of renewable energy to the grid}

$20 \%$ of renewable energy is always supplied to the grid and the rest is supplied to cover a part or all of the desalination electricity needs. 
3. Priority to desalination, but also selling photovoltaic electricity up to $20 \%$ to the grid

First the desalination energy requirements are covered. Then the renewable energy surplus is supplied to the grid. Due to higher FIT (feed-in-tariff) for PV electricity, the operator chooses to sell PV electricity as priority in case both wind turbines and solar PVs are installed and in operation.

There is also a 4th case considered in this study, which assesses conventional desalination without utilizing renewable energy to assess how the renewable energy penetration affects the water production cost.

\subsection{Way forward}

The policy options mentioned in the previous section need to be evaluated and compared in terms of economic terms and renewable energy penetration. This asks for the development of a methodology, the creation of a model as well as an extensive data collection and analysis. Then, three representative islands (small, medium, large in size and water demand) are selected for assessment.

\section{Methodology}

The methodology and the main steps followed in this study are illustrated in the subsequent flow chart (Fig. 1). Based on this flowchart, the model is programmed. The essential model specifications include different desalination plant capacities sufficient to supply the islands' entire water demand ${ }^{3}$, selection of RET plants and capacities supplying the electricity for desalination and to the grid, energy balances of the system (desalination system connected to the grid using RES and fossil fuels only when necessary), calculation of the desalinated water production cost and electricity generating costs. Ultimately the water selling price will be enumerated to ensure the viability of the investment for the Hellenic State and the profitability for the investor.

The multiparameter dimensioning tool is created using Visual Basic and there is an Excel based (user friendly) interface, where the user adds the necessary input data and runs the model. This methodology is applied on 3 characteristic islands (large, medium, small in size and water/electricity demand) and several scenarios regarding the RES penetration are constructed and carried out.

\subsection{Data requirements and demand analysis}

Key input data required for the analysis are:

- Tourism and demographic developments to project the annual electricity and water demand (with load variation over the year) for a 20 year time horizon. These data are provided by the Aegean Energy Agency.

- Wind availability and solar irradiation time series, technoeconomic performance characteristics of RET, desalination technologies and other infrastructure and storage components (investment, conversion efficiencies, intensities, O\&M costs, etc.). Capacity factors are subsequently calculated and used to identify the potential generation from RES and the corresponding costs on an hourly basis.

- FITs, fuel prices, subsidies and taxes, electricity and water tariffs, discount rate

\footnotetext{
${ }^{3}$ Groundwater and rainfall should not be considered as a source for potable water, rather than water for irrigation.
}

The experience gained from other islands (e.g Milos) indicates that the comfort of having desalinated water increases the demand [5]. Thus it is assumed that the future demand will be $1.5^{4}$ times the present per person in order to have a reserve margin. The distribution of the tourists throughout the year, the annual growth of tourism as well of the population are taken into account.

In order to dimension the desalination unit properly, the water demand should be distributed throughout each hour of the year in order to come up with the estimated peak daily demand. To do this, a non-dimensional demand for water and electricity is introduced (see Equation (1)). This is a factor that considers the distribution of electricity demand. Based on that the water demand is distributed.

Equation (1)

$f_{w / e}=\frac{\text { Hourly Electricity Demand }(H E D)}{\text { Peak Electricity Demand }(P E D)}$

The mean hourly water demand is being calculated as: Equation (2)

Mean Hourly Water Demand $(M H W D)=\frac{\text { Annual Water Demand }}{8760}$

And the hourly water demand:

Equation (3)

Hourly Water Demand $(H W D)=\frac{M H W D * f_{w / e}}{\text { mean } f_{w / e}}$

From the hourly distribution of the electricity demand, the hourly water demand is calculated (Equations (1)-(3)). From this the minimum water demand is being subtracted. Thereafter a $50 \%$ increase is considered. Then the minimum is added again. This is done in order to create a time series where the hours with higher demand get higher increase as compared to those with lower demand. This is introduced because peak water demand during the touristic period is more intense than the distribution of the electricity demand. Thus a different distribution is followed. To illustrate this, the increased hourly water demand is calculated as shown in the Equation (4):

Equation (4)

Increased $H W D=[H W D-\min H W D]^{*} 1,5+\min H W D$

Tourism plays major role in the distribution of the water demand. Increasing tourism causes a strong and seasonal water demand [29]. To validate the relation of electricity demand and tourism, monthly data regarding the number of rooms and their usage are gathered for each island. Tourism distribution and electricity variation are then plotted in the same graph. If these two match, the electricity distribution can be used to calculate the water distribution. If there is no match, the distribution of another island's electricity demand that gives a better match is used [53].

Another important factor in the dimensioning of the desalination unit is the capacity of water storage tanks. These are $15.800 \mathrm{~m}^{3}$ on Patmos, $1000 \mathrm{~m}^{3}$ on Lipsoi and $2050 \mathrm{~m}^{3}$ on Thirasia [53]. Based on technical characteristics and reserve margins, it is assumed that the minimum storage should be $20 \%$ of the tank capacity [5]. This criterion is used for all islands in order to ensure the same reliability of the desalination unit. The tool calculates the percentage of the maximum daily water demand to ensure a minimum $20 \%$ storage.

\footnotetext{
$450 \%$ increase is based on the experience gained from similar dimensioning on Milos Island. This value is also used in agreement with the Hellenic Ministry of
} Energy, Environment and Climate Change. 


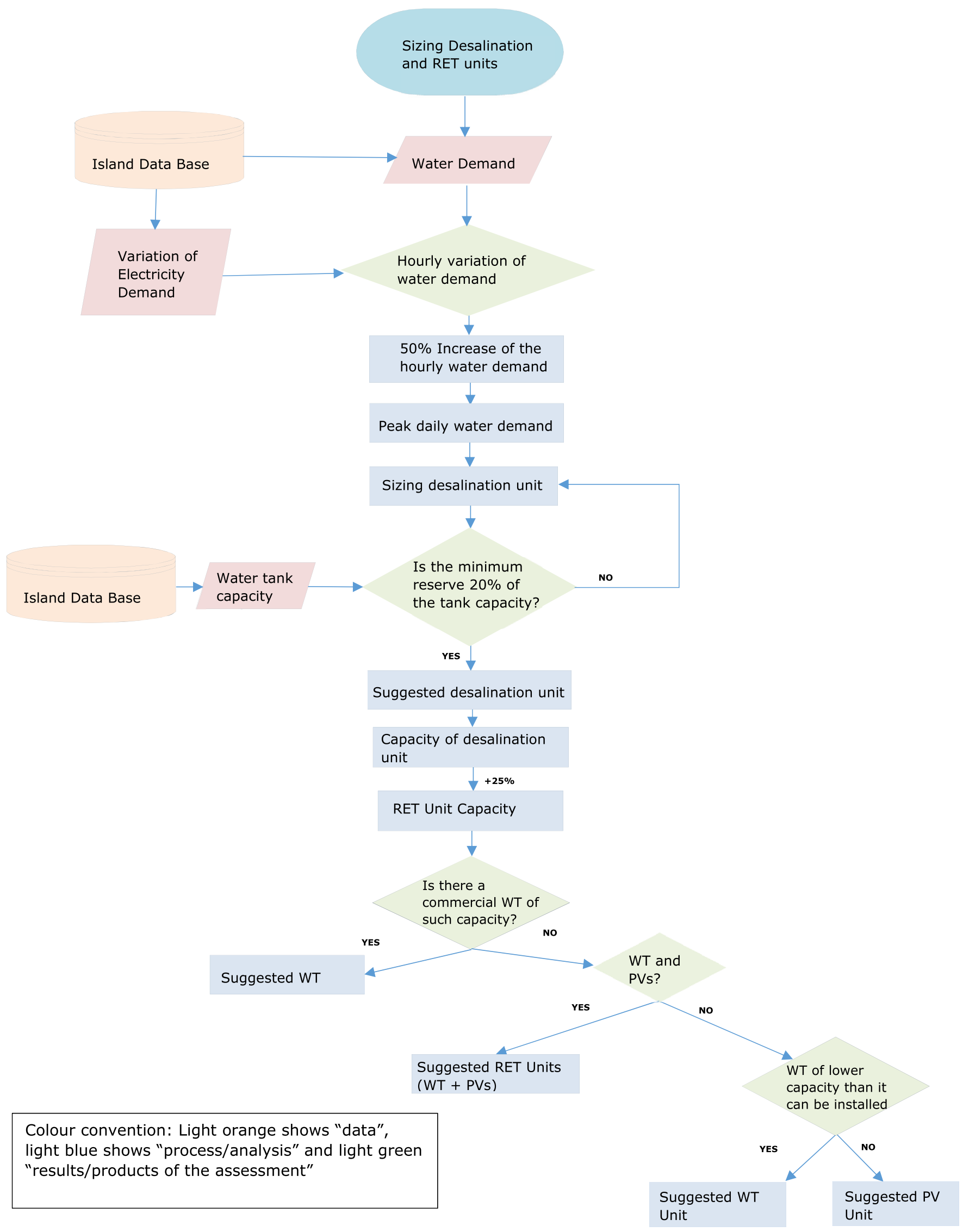

Fig. 1. Flow chart methodology. 
This means that it is not necessary that the unit is designed to produce the peak water demand, as this would lead to over dimensioning of the unit and inherently increased costs.

\subsection{Technology characteristics}

The costs of key technologies and basic economic parameters are summarized in Tables 2 and 3 below Refs. [5, 21-23]. Wind turbines' costs range from 1500 to $4000 € / \mathrm{kW}$. The larger the wind turbine the smaller the cost per installed kW. According to the PV market in Greece, PV costs do not vary for these kind of small scale installations. The capacity factors of the RET vary from one island to another and thus not included in the report.

\subsection{System considerations}

Based on the minimum required capacity of the desalination unit, 4 sub units of the same capacity are chosen to be installed since not all of the units are needed to be operating throughout the year. This guarantees that technical problems can be solved and maintenance carried out in different stages; thus higher technical availability of ca $85 \%$ can be achieved [50]. The desalination units chosen for this study are operating at standard points which are:

Subunit 1 function : $0.25 *$ min required capacity $\left(\mathrm{m}^{3} / \mathrm{hr}\right)$

Subunits 1 and 2 function : $0.5^{*}$ min required capacity $\left(\mathrm{m}^{3} / \mathrm{hr}\right)$

Subunit 1, 2 and 3function: $0.75 *$ min required capacity $\left(\mathrm{m}^{3} / \mathrm{hr}\right)$

\section{Subunit 1, 2, 3 and 4 function}

$$
\text { : min required capacity }\left(\mathrm{m}^{3} / \mathrm{hr}\right)
$$

It should be stated that the desalination units can be operating nonstop. To avoid producing water that cannot be stored, an upper limit of water production is introduced. This limit is set by the water tank storage. If the storage exceeds $90 \%$ of the capacity, the desalination unit is set in a "stand by" mode until the storage levels decrease below $90 \%$. In the case that storage is lower than $90 \%$, a comparison is made between daily water demand and the capacity of the desalination unit and:

- if the daily demand is lower than $\left(0.25^{*}\right.$ capacity of the unit), $\left(0.25^{*}\right.$ capacity of the unit) $\mathrm{m}^{3}$ will be produced

- if the daily demand is greater than $\left(0.25^{*}\right.$ capacity of the unit) and lower than $\left(0.5^{*}\right.$ capacity of the unit), $\left(0.5^{*}\right.$ capacity of the unit) $\mathrm{m}^{3}$ will be produced

- etc.

Table 2

Costs of technologies.

\begin{tabular}{|c|c|c|}
\hline Technology & Investment cost & O\&M costs \\
\hline $\begin{array}{l}\text { Desalination } \\
\text { unit }\end{array}$ & $1000\left(€ / \mathrm{m}^{3} /\right.$ day $)$ & $\begin{array}{l}0.3\left(€ / \mathrm{m}^{3}\right)+\text { workforce } \\
20-60 \mathrm{k} € \text { depending } \\
\text { on the capacity }\end{array}$ \\
\hline Wind turbine & $1500-4000(€ / \mathrm{kW})$ & $0.015(€ / \mathrm{kWh})$ \\
\hline $\begin{array}{l}\text { Solar } \\
\text { photovoltaics }\end{array}$ & $3500(€ / \mathrm{kW})$ & $5.9(€ / \mathrm{kW} /$ year $)$ \\
\hline
\end{tabular}

Table 3

Main economic parameters.

\begin{tabular}{ll}
\hline Wind energy feed in tariff & $0.09945(€ / \mathrm{kWh})$ \\
Solar PV Feed in tariff & $0.26485(€ / \mathrm{kWh})$ \\
Grid electricity price & $0.08785(€ / \mathrm{kWh})$ \\
Discount rate & $6 \%$ \\
Desalination and RET lifetime & 20 years \\
\hline
\end{tabular}

The total energy requirements of the RO units proposed are $4 \mathrm{kWh} / \mathrm{m}^{3}[9,50]$. It should be noted that the actual energy consumption depends on the pumping distances and thus this may vary from one island to another. Based on the desalination's energy requirements, the RET unit is dimensioned. The RET unit power capacity is $25 \%$ more than the power capacity of the desalination unit. Solar irradiation and wind speed time series for each island are used to calculate the energy yield on an hourly basis using commercial wind turbine models and solar PVs. The renewable energy time series are provided by the Aegean Energy Agency ${ }^{5}$. Efficiencies and power curves of different RET are introduced in the model in order to estimate the yield [45]. Based on the availability of the RES and the commercial availability of RET units, the selection is based on least cost solutions over the time of the project.

\subsection{Synopsis of scenarios}

The tool developed accounts for several parameters and runs several case studies for various factors. Here all the significant parameters are synopsized. 3 islands are considered (large, medium, small), 4 scenarios regarding the interpretation of the legislation framework for renewables, various scenarios regarding the RET penetration.

- 3 islands (size and water demand)

$>$ Patmos (large)

$>$ Lipsoi (medium)

$>$ Thirasia (small)

- 4 scenarios regarding the RES law interpretation

$>$ Priority to desalination

$>$ Priority to selling $20 \%$ of renewable energy to the grid

$>$ Priority to desalination, but also selling photovoltaic electricity up to $20 \%$ to the grid

$>$ Conventional desalination without utilizing renewable energy

- Scenarios for RET (Relation between the installed capacity of wind turbines and solar PVs). The installed RET capacity consists of:

$>100 \% \mathrm{WT}$,

$>75 \%$ WT-25\% PV,

$>50 \%$ WT- $50 \%$ PV,

$>25 \%$ WT-75\% PV and

$>100 \% \mathrm{PV}$

\section{Results}

The following sections show a set of graphs summarizing the results for the three legislative scenarios and a business-as-usual scenario based on conventional desalination for each of the three representative islands and for various level of renewable electricity generation. Critical figures are generated from the model runs. These include the desalinated water production cost, the percentage of desalination energy requirements covered from RET, the

\footnotetext{
${ }^{5}$ Aegean Energy Agency: http://www.aegean-energy.gr/en/.
} 
percentage of unused energy produced from RET and economicinvestment indicators, such as IRR (internal rate of return), NPV (net present value) of the investment and PBP (pay-back period). Based on the economic indicators, a suggested selling price is proposed so as the investment is both sustainable for the Hellenic State and profitable for potential investors. A selection of those is presented.

The graphs on the top show the percentage of desalination's energy requirements covered by $\mathrm{RE}$, while the bottom graphs present the water selling price. In the $\mathrm{x}$-axis the penetration of renewables in terms of installed capacity from the left to the right goes from $100 \%$ WT to $100 \%$ Solar PVs. Section on techno-economic findings of the study and on sensitivity analyses conclude the Results.

\subsection{Scenario 1 - priority to desalination}

From the first graph, it can be seen that the higher the wind power penetration, the higher the percentage of the desalination energy requirements supplied by RES. This percentage reaches $60 \%$ if the renewable energy is only generated by wind turbines whilst this figure does not exceed $30 \%$ if it is only solar PVs (Fig. 2). This is of course attributed to the higher capacity factor of the wind turbines per installed $\mathrm{kW}$.

Regarding the economics, it should be highlighted that a higher wind power penetration implies lower selling price to achieve a certain IRR. The selling price ranges from $1.45 € / \mathrm{m}^{3}$ for the large island while the selling price is about $2.6 € / \mathrm{m}^{3}$ at the smallest island (Fig. 3). This is mainly because of the higher cost per installed $\mathrm{kW}$ as the wind turbine size is getting smaller. It is noteworthy that the selling price on Thirasia does not vary significantly from the $100 \%$ wind to $100 \%$ solar penetration scenario. This is due to the fact that specific investment costs (per $\mathrm{kW}$ ) are inversely related to unit sizes (smaller turbines signify higher costs per installed $\mathrm{kW}$ ) Thus, solar photovoltaics are a competitive power source in such cases.

\subsection{Scenario 2 - priority to selling $20 \%$ of renewable energy to the} grid

Compared to the first scenario, the energy covered by RES is of course lower since the energy is first supplied (actually sold) to the grid and the remaining energy is provided to cover the energy required by the desalination unit. In fact, if the RET is a WT, the desalination requirements covered by the RET do not exceed $55 \%$

Percent of the Desalination Energy Requirements covered by RES

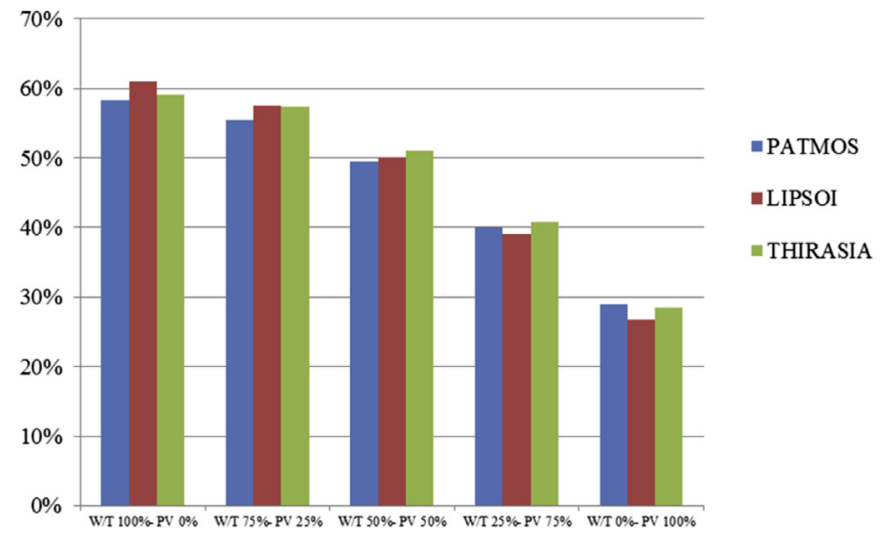

Fig. 2. Desalination requirements covered by RES - Scenario 1.

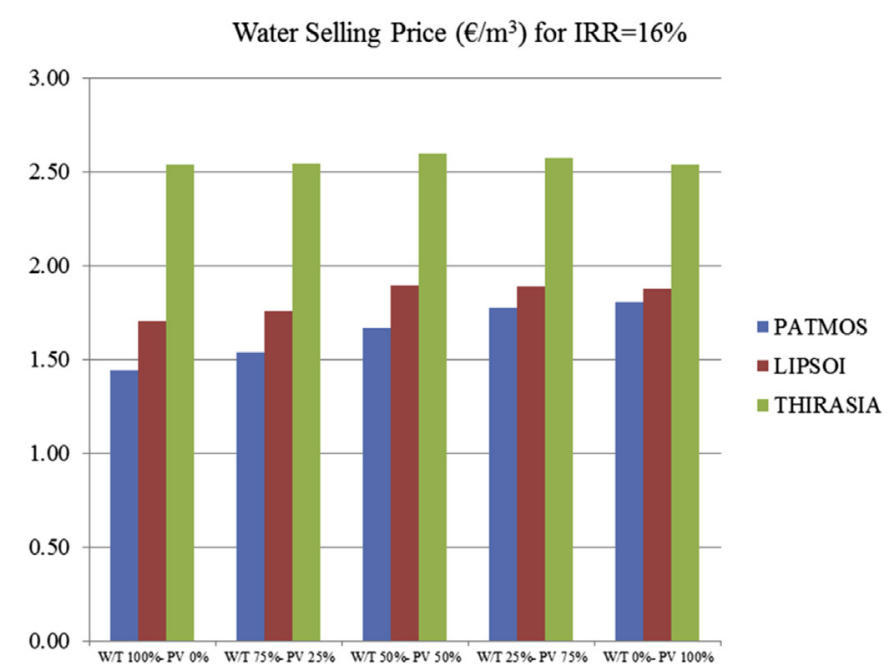

Fig. 3. Water selling price - Scenario 1.

on all islands, whilst in the first scenario the same value reached approximately $60 \%$ Fig. 4 . The selling price is slightly lower because the investors are making some profit from the Feed-in tariff scheme Fig. 5.

\subsection{Scenario 3 - priority to desalination and solar PV up to $20 \%$}

The contribution of RET in covering desalination energy demand is the same as in the first scenario since the desalination is prioritized Fig. 6. However, the selling price is lower since the PV energy is prioritized in case both PV and WT are installed since PVs Feed-in Tariff is higher Fig. 7.

From the above, it should be highlighted that the higher the wind power penetration, the higher the percentage of the desalination energy requirements covered from RES. Also, higher wind power penetration implies lower selling price to achieve a certain IRR. The selling price ranges from $1.45 € / \mathrm{m}^{3}$ for the large island while the selling price is about $2.6 € / \mathrm{m}^{3}$ at the smallest island.

\subsection{Scenario $4-$ conventional desalination}

If the desalination uses energy based on fossil fuels, the selling price of the water is lower than the previous scenarios. This is due to the high installation costs of WT and PVs. Another reason is the

Percent of the Desalination Energy Requirements covered by RES

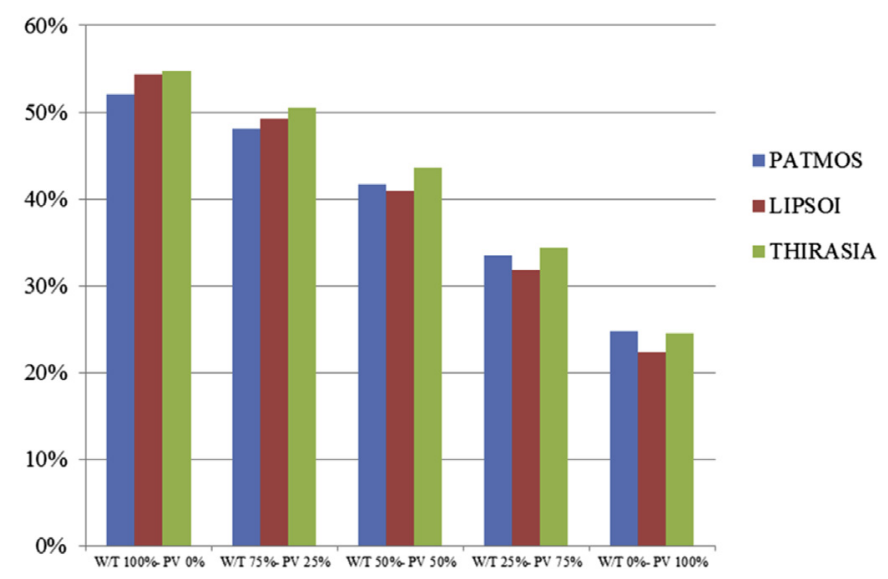

Fig. 4. Desalination requirements covered by RES - Scenario 2. 
Water Selling Price $(€ / \mathrm{m} 3)$ for IRR $=16 \%$

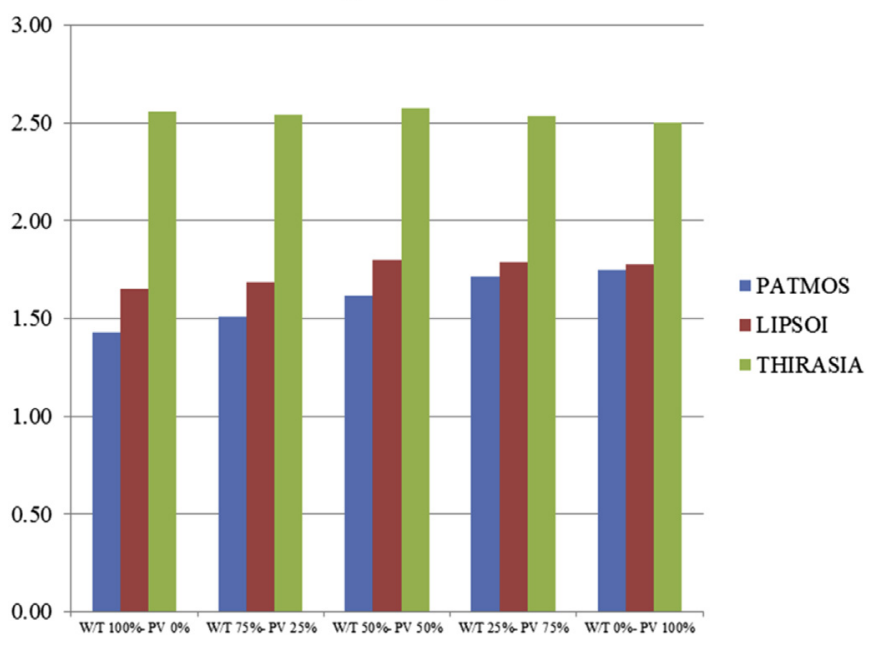

Fig. 5. Water selling price - Scenario 2 .

Percent of the Desalination Energy Requirements covered by RES

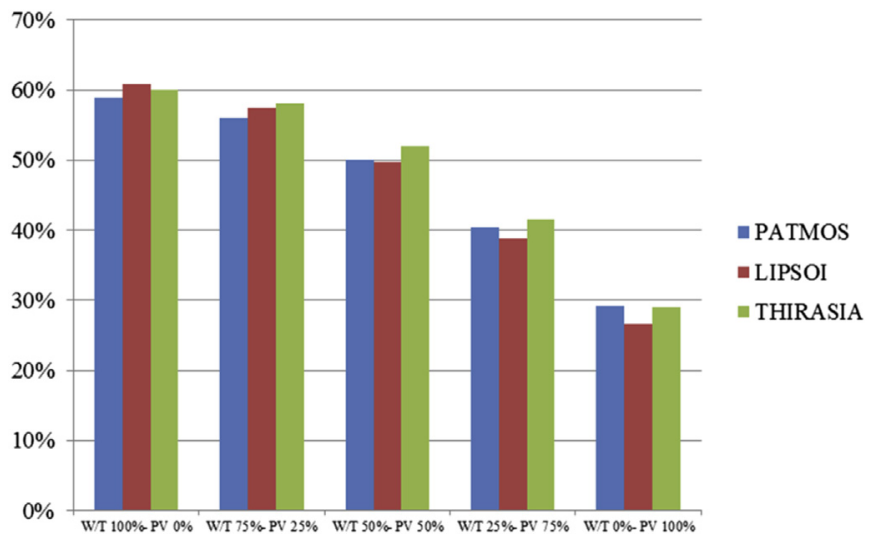

Fig. 6. Desalination requirements covered by RES - Scenario 3.

hidden costs in the fossil based generation which are not being accounted in this comparison. The selling price of water is lower due to the fact that the electricity price is the same as on the mainland despite the higher generating costs on the islands which consume mainly diesel and heavy oil for their operation [26].

To illustrate, the use of portable generator units which are transferred from one island to another is a common practice. The current cost of electricity production using generators is extremely high [39] ranging from $200 € /$ MWh to $1000 € /$ MWh on very small islands [24]. Also, environmental costs from burning fossil fuel are not considered (e.g. imported diesel and heavy oil emit severe air pollutants). Hence, the electricity price on the islands and its actual production cost are not related.

For the analysis, 3 different IRRs are chosen ${ }^{6}$. The tool is able to indicate at which selling prices the IRR becomes $12 \%, 16 \%$ and $20 \%$. $12 \%$ is an Internal Rate of Return satisfactory for the public sector, $20 \%$ for an investor to have a very profitable investment, while $16 \%$

\footnotetext{
${ }^{6}$ Both IRR and Net Present Value are enumerated by the tool. According to [19], the IRR gives the private investor's point of view and the NPV the society's point of view. Thus, the tool gives the possibility to the user to choose which indicator he wants to consider.
}

Water Selling Price $\left(€ / \mathrm{m}^{3}\right)$ for $\mathrm{IRR}=16 \%$

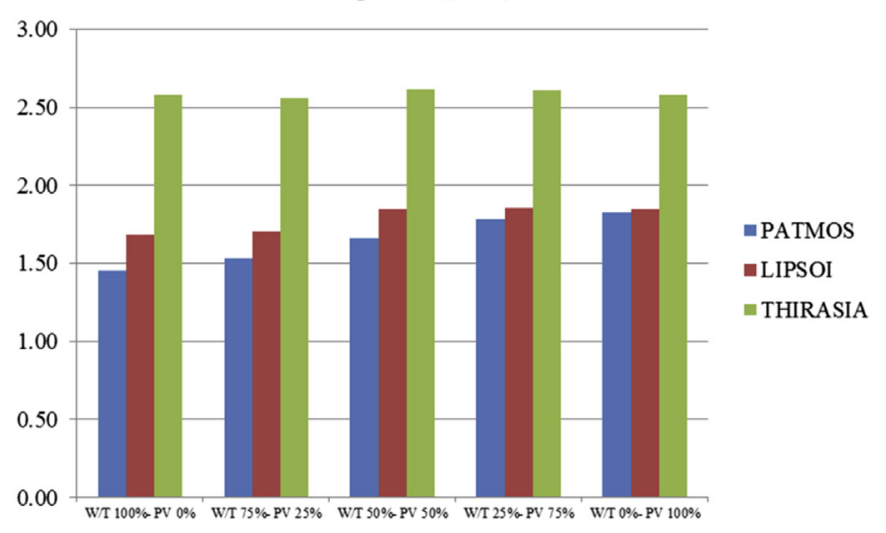

Fig. 7. Water selling price - Scenario 3.

Water selling price $\left(€ / \mathrm{m}^{3}\right)$ for $\mathrm{IRR}=12 \%, 16 \%, 20 \%$

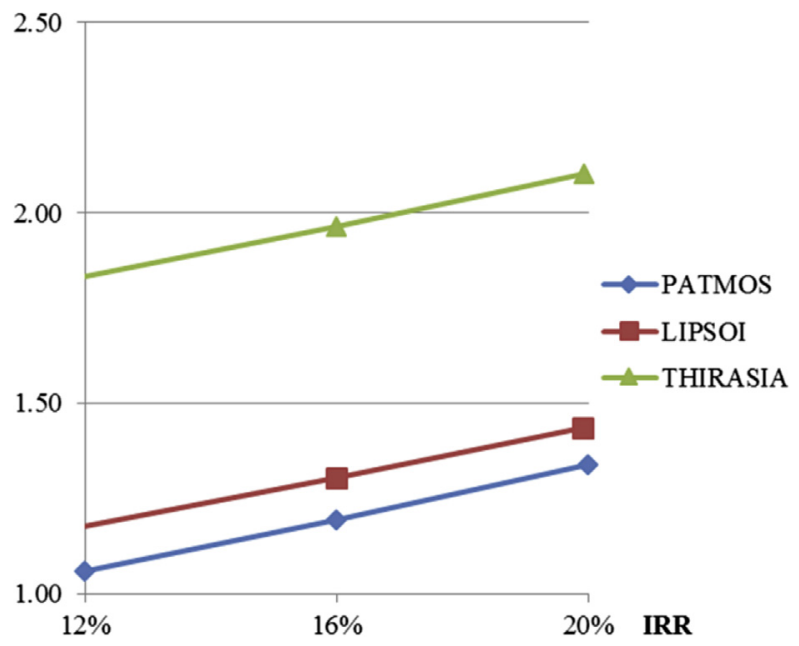

Fig. 8. Water selling price based on fossil fuelled desalination.

is an average so that the investment is both sustainable for the Hellenic state and profitable for investors Fig. 8.

\subsection{Techno-economic results}

In order to prioritize the desalination but also give the possibility to investors to prioritize PV production in case they have installed both wind and solar power, the third scenario proceeds for further evaluation. The final results after dimensioning desalination and RET units are depicted in the following tables. Table 4 synopsizes the capacities of both technologies. The water quantity that is transported annually to the islands as well as the water quantity (such as to cover present and future water demand as explained in the methodology) that is predicted by the tool are depicted in while Table 5 displays the suggested water selling price ${ }^{7}$.

\subsection{Sensitivity analysis}

A sensitivity analysis is carried out by the tool for the large island in order to assess how the different parameters influence the

\footnotetext{
7 As mentioned the water selling price is calculated to achieve an IRR equal to 16\%. The Payback Period is about 6.5 years for all the cases.
} 
Table 4

Proposed techno-economic characteristics of desalination and RET units for the selected islands.

\begin{tabular}{|c|c|c|c|c|c|}
\hline Selected islands & $\begin{array}{l}\text { Transported water } \\
\text { quantity }\left(\mathrm{m}^{3}\right)\end{array}$ & $\begin{array}{l}\text { Predicted capacity } \\
\left(\mathrm{m}^{3}\right)\end{array}$ & $\begin{array}{l}\text { Desalination unit } \\
\text { capacity }\left(\mathrm{m}^{3} / \text { day }\right)\end{array}$ & $\begin{array}{l}\text { Total capacity } \\
\left(\mathrm{m}^{3} / \text { day }\right)\end{array}$ & RET units \\
\hline Patmos & 253600 & 419736 & $4 \times 500$ & 2000 & $1 \mathrm{WT} 330 \mathrm{~kW}$ and PV $86 \mathrm{~kW}$ \\
\hline Lipsoi & 40900 & 88168 & $4 \times 100$ & 400 & $1 \mathrm{WT} 50 \mathrm{~kW}$ and PV $33 \mathrm{~kW}$ \\
\hline Thirasia & 18000 & 23276 & $4 \times 25$ & 100 & PV $20.8 \mathrm{~kW}$ \\
\hline
\end{tabular}

Table 5

Proposed water selling price for the suggested islands.

\begin{tabular}{lll}
\hline $\begin{array}{l}\text { Selected } \\
\text { islands }\end{array}$ & $\begin{array}{l}\text { Desalinated water } \\
\text { production cost }\left(€ / \mathrm{m}^{3}\right)\end{array}$ & $\begin{array}{l}\text { Water selling } \\
\text { price }\left(€ / \mathrm{m}^{3}\right)\end{array}$ \\
\hline Patmos & 1.17 & 1.59 \\
Lipsoi & 1.41 & 1.88 \\
Thirasia & 2.18 & 2.57 \\
\hline
\end{tabular}

water production cost, as shown in Fig. 9. These parameters are the investment costs for RET units, the desalination investment cost, cost of the chemicals, cleaning and operating costs of the desalination unit, predicted water demand, fuel price and life time of the project. The impact of each parameter to the water cost is enumerated by varying it $\pm 10 \%$ while keeping the rest constant. The most significant ones are predicted water demand, electricity price, lifetime of the investment, and O\&M costs of the unit (chemicals etc.) since a minor change in their values alters notably the water production cost.

\section{Discussion}

From Fig. 9 one may observe that the water selling price is significantly lower than the current water supply costs (referred to cost for marine transportation of water to the islands) which is being transported from the mainland and this would subsequently save a great deal of the budget allocated for water supply on the islands by the Hellenic State Fig. 10.

The methodology and the tool developed for this study contribute to the sizing of desalination and RET which can be integrated to minimize water and energy costs as well as environmental impacts. This tool considers and introduces various crucial parameters -when it comes to the sizing of desalination and RET units-that have not been considered in previous studies; tourism and demographic variation and growth and detailed projection of

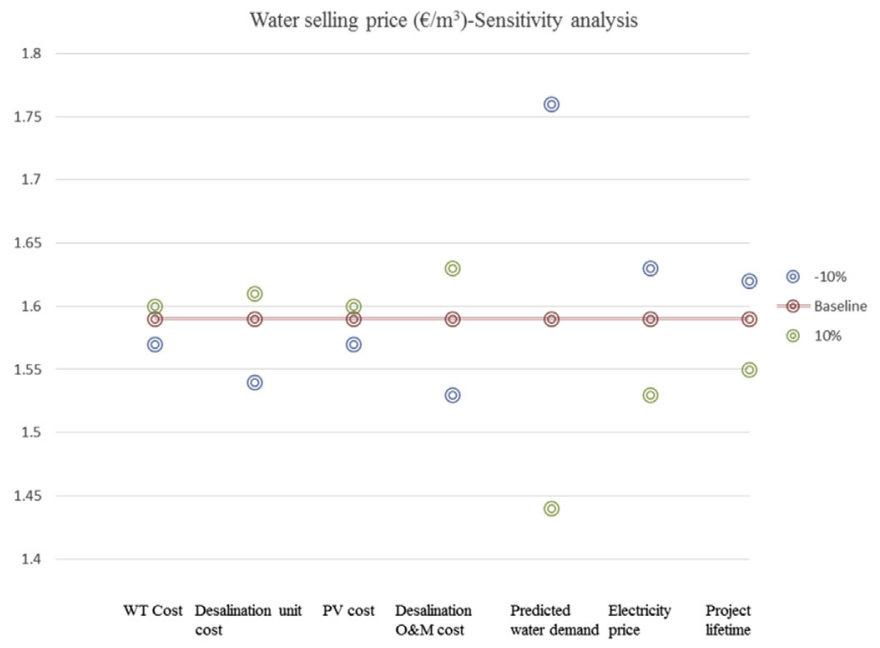

Fig. 9. Water selling price - Sensitivity analysis. the water demand, water tank capacities, electricity load variation, legislation framework, actual wind and solar time series, hourly energy balance, sustainable water pricing and land availability.

It constitutes a planning and design tool for the Hellenic Ministry of Environment, Energy and Climate Change as well as the Hellenic Ministry of Shipping. The model is used to dimension units on 3 characteristic islands. Likewise, it can be implemented on other arid islands to provide capacities, energy balances and economic and financial indicators.

More than that, it is a tool that can be used by governments, energy agencies and utilities that consider investing in desalination units using renewable energy technologies around the world in regions that face water scarcity and at the same time have abundant renewable energy potential.

It should be mentioned that the siting criteria for setting up a desalination plant and the RET units should be followed in order to comply with the legislation framework and to diminish environmental impact. Apart from the high energy consumption of the desalination technologies, there is also the brine disposal which is recognized as the other major environmental impact [47]. Thus environmental impact assessments (EIA) should be carried out before setting up a plant.

The size of the desalination units does not exceed $2000 \mathrm{~m}^{3} /$ day on the larger island studied. To give an order of magnitude, the size of Dhekelia RO desalination plant in Cyprus reaches $60000 \mathrm{~m}^{3} /$ day. According to the EIA of the Cyprus Department of Fisheries and Marine Research, it is observed that the marine environment is affected within a radius of $200 \mathrm{~m}$ of the outfall point [40]. Hence, a proper EIA including mathematical modelling for the brine disposal would diminish the adverse impact of the discharged concentrated salt water [12].

\section{Conclusions and next steps}

To conclude, the water scarcity problem on the Greek islands is severe. The transportation of water from the mainland burdens economically the Hellenic state and in many cases it deteriorates the quality of life on the islands and affects tourism negatively.

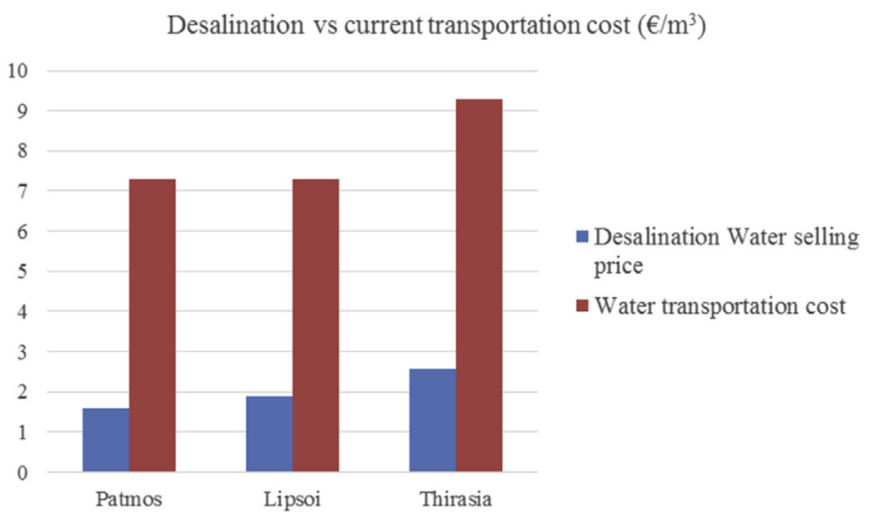

Fig. 10. Comparison between desalination price and price of transported water. 
Desalination technology is a suitable solution to this problem. At the same time, the renewable energy potential of the islands should be utilized in order to provide clean energy and avoid overloading the already congested autonomous systems. The proposed desalination units are not designed to only replace the water shipments but supply the entire water demand of the islands as projected within 20 years' time perspective.

The analyses suggest that for larger islands the installation of WT is the preferred solution while solar PVs can be installed additionally. In smaller islands the RET unit selection is not that clear since the installation cost per $\mathrm{kW}$ of smaller WT is significantly higher in comparison with the larger ones. In that case, solar PVs are competitive and siting criteria play an important role in the RET selection.

The water selling price is significantly lower than the price of transported water in all cases and the implementation of such a project would be beneficial for all involved stakeholders; the Hellenic State, investors, and of course islanders and tourists who will be able to drink potable water without being obliged to spend a significant amount of money on bottled water. The latter is an important issue often ignored in discussions related to water value and costs. The over-consumption of bottled water on the islands due to the lack of potable water from the local water supply system network is a major issue and the amounts of money being spent annually are paramount.

Another critical matter is the legislation framework that concerns the siting of the units. Land availability and suitability is often an issue on these arid islands as the framework adds several constraints on the siting of the units. On-site studies of the suitable locations constitute the next step that follows this technoeconomic pre-feasibility analysis. Moreover, the externalities of fossil fuel generation as well as those of RETs should be evaluated.

\section{Acknowledgments}

Giannis Bouzas (ITA Group) for his valuable guidance and George Emmanouilidis (Aegean Energy Agency) for his contribution in data collection.

\section{References}

[1] Al-Nory M, El-Beltagy M. An energy management approach for renewable energy integration with power generation and water desalination. Renew Energy 2014;72:377-85. http://dx.doi.org/10.1016/j.renene.2014.07.032.

[2] Asimakopoulos D. Desalination using renewables on arid islands. 2010.

[3] Baawain MS, Choudri BS, Ahmed M, Purnama A. Recent progress in desalination, environmental and marine outfall systems. Springer; 2015.

[4] Bennett A. Sustainable desalination: renewable energy in desalination systems. Filtr Sep 2011;48:24-7. http://dx.doi.org/10.1016/S0015-1882(11) 70208-7.

[5] Bouzas I. Project manager ITA group, responsible for the desalination units on Milos. 2014.

[6] Bouzas I. Desalination with the use of wind energy in Milos Island. International Technological Applications (ITA) S.A; 2010.

[7] Bundschuh Jochen, Hoinkis Jan. Renewable energy applications for freshwater production. Hoboken: Taylor and Francis; 2012.

[8] Chen JP, Chian ESK, Sheng P-X, Nanayakkara KGN, Wang LK, Ting Y-P. Desalination of seawater by reverse osmosis. In: DEE DLKW, PE, Chen DJP, DEE DYTH, PE, Shammas DNK, editors. Membrane and desalination technologies, handbook of environmental engineering. Humana Press; 2011. p. 559-601.

[9] Chung T-S, Zhang S, Wang KY, Su J, Ling MM. Forward osmosis processes: Yesterday, today and tomorrow. Desalination 2012;287:78-81. http:/ dx.doi.org/10.1016/j.desal.2010.12.019. Special issue in honour of Professor Takeshi Matsuura on his 75th birthday.

[10] Clarke DP, Al-Abdeli YM, Kothapalli G. Multi-objective optimisation of renewable hybrid energy systems with desalination. Energy 2015;88:457-68. http://dx.doi.org/10.1016/j.energy.2015.05.065.

[11] Duić N, da Graça Carvalho M. Increasing renewable energy sources in island energy supply: case study Porto Santo. Renew Sustain Energy Rev 2004;8: 383-99. http://dx.doi.org/10.1016/j.rser.2003.11.004.

[12] Einav R, Lokiec F. Environmental aspects of a desalination plant in Ashkelon. Desalination 2003;156:79-85. http://dx.doi.org/10.1016/S0011-9164(03)
00328-X. Joint EDS, WSTA and IWA conference on desalination and the environment fresh water for All UN international year of fresh Water 2003.

[13] Eltawil MA, Zhengming Z, Yuan L. A review of renewable energy technologies integrated with desalination systems. Renew. Sustain. Energy Rev 2009;13: 2245-62. http://dx.doi.org/10.1016/j.rser.2009.06.011.

[14] EYDAP. Corporate announcement regarding the billing scale [WWW document]. URLhttp://www.eydap.gr/en/news/PressRelease/?id=a854f2ef-82974686-abee-a3380118e52e. 2013 (accessed 9.16.15).

[15] Fane AG, Tony, Wang R, Jia Y. Membrane technology: Past, present and future. In: DEE DLKW, PE, Chen DIP, DEE DY-TH, PE, Shammas DNK, editors. Membrane and desalination technologies, Handbook of environmental Engineering. Humana Press; 2011. p. 1-45.

[16] Ghaffour N, Missimer TM, Amy GL. Technical review and evaluation of the economics of water desalination: current and future challenges for better water supply sustainability. Desalination 2013;309:197-207. http:// dx.doi.org/10.1016/j.desal.2012.10.015.

[17] Greek Ministry of Shipping, Maritime Affairs and Aegean. General secretariat for the Aegean and island policy [WWW document]. URLhttp://www.ypai.gr/ site/home/Basic +Menu/Initiatives + of + Growth/Water+feeder.csp jsessionid =c0a81e0a30da2def596bb4cf495b955ad47f3002c295. e38Pch0Kbh4Nc400bh8Sbx4Lb41ynknvrkLOlQzNp65In0? mode $=$ print \&pagenum $=1.2011$ (accessed 10.20.14).

[18] Gude VG, Nirmalakhandan N, Deng S. Desalination using solar energy: towards sustainability. Energy 2011;36:78-85. http://dx.doi.org/10.1016/ j.energy.2010.11.008.

[19] Hajdasinski MM. Technical note-the internal rate of return (IRR) as a financial indicator. Eng Econ 2004;49:185-97. http://dx.doi.org/10.1080/ 00137910490453437.

[20] Hossam-Eldin A, El-Nashar AM, Ismaiel A. Investigation into economical desalination using optimized hybrid renewable energy system. Int J Electr Power Energy Syst 2012;43:1393-400. http://dx.doi.org/10.1016/ j.ijepes.2012.05.019.

[21] HTSO. Hellenic transmission system operator [WWW document]. 2015. URLhttp://www.desmie.gr/nc/en/home/.

[22] IPCC. Climate change 2001: mitigation: contribution of working group III to the third assessment report of the intergovernmental panel on climate change. New York: Cambridge University Press: 2001.

[23] IRENA. Renewable energy technologies: cost analysis series, solar photovoltaics. 2012.

[24] Kaldellis JK, Gkikaki A, Kaldelli E, Kapsali M. Investigating the energy autonomy of very small non-interconnected islands: a case study: Agathonisi, Greece. Energy Sustain Dev 2012;16:476-85. http://dx.doi.org/10.1016/ j.esd.2012.08.002.

[25] Kaldellis JK, Kavadias KA, Kondili E. Renewable energy desalination plants for the Greek islands-technical and economic considerations. Desalination 2004;170:187-203. http://dx.doi.org/10.1016/j.desal.2004.01.005.

[26] Kaldellis JK, Zafirakis D. Present situation and future prospects of electricity generation in Aegean Archipelago islands. Energy Policy 2007;35:4623-39. http://dx.doi.org/10.1016/j.enpol.2007.04.004.

[27] Kalogirou SA. Seawater desalination using renewable energy sources. Prog Energy Combust Sci 2005;31:242-81. http://dx.doi.org/10.1016 j.pecs.2005.03.001.

[28] Karagiannis IC, Soldatos PG. Current status of water desalination in the Aegean Islands. Desalination 2007;203:56-61. http://dx.doi.org/10.1016/ j.desal.2006.04.006. EuroMed 2006 conference on desalination strategies in south Mediterranean countries.

[29] Karavitis CA, Kerkides P. Estimation of the water resources potential in the island system of the aegean Archipelago, Greece. Water Int 2002;27:243-54. http://dx.doi.org/10.1080/02508060208686998.

[30] Khawaji AD, Kutubkhanah IK, Wie J-M. Advances in seawater desalination technologies. In: Desalination, European desalination society and center for research and technology Hellas (CERTH), Sani Resort 222-25 April 2007 Halkidiki, Greece European desalination society and center for research and technology Hellas (CERTH), Sani Resortvol. 221; 2008. p. 47-69. http:// dx.doi.org/10.1016/j.desal.2007.01.067.

[31] Kondili E, Kaldellis JK, Paidousi M. A multicriteria analysis for the optimal desalination-RES system. Special focus: the small Greek islands. Desalination Water Treat 2012;51:1205-18. http://dx.doi.org/10.1080/ 19443994.2012 .715423$.

[32] Koroneos C, Dompros A, Roumbas G. Renewable energy driven desalination systems modelling. J Clean Prod 2007;15:449-64. http://dx.doi.org/10.1016/ j.jclepro.2005.07.017.

[33] Koutroulis E, Kolokotsa D. Design optimization of desalination systems power-supplied by PV and W/G energy sources. Desalination 2010;258: 171-81. http://dx.doi.org/10.1016/j.desal.2010.03.018.

[34] Ma Q Lu H. Wind energy technologies integrated with desalination systems: review and state-of-the-art. Desalination 2011;277:274-80. http://dx.doi.org/ 10.1016/j.desal.2011.04.041.

[35] Mentis D. Electrifying Greece with solar and wind energy. Therm Sci 2014;18: 709-20. http://dx.doi.org/10.2298/TSCI1403709M.

[36] Mezher T, Fath H, Abbas Z, Khaled A. Techno-economic assessment and environmental impacts of desalination technologies. Desalination 2011;266: 263-73. http://dx.doi.org/10.1016/j.desal.2010.08.035.

[37] Novosel T, Ćosić B, Krajačić G, Duić N, Pukšec T, Mohsen MS, et al. The influence of reverse osmosis desalination in a combination with pump storage 
on the penetration of wind and PV energy: a case study for Jordan. Energy 2014;76:73-81. http://dx.doi.org/10.1016/j.energy.2014.03.088.

[38] Novosel T, Ćosić B, Pukšec T, Krajačić G, Duić N, Mathiesen BV, et al. Integration of renewables and reverse osmosis desalination - case study for the Jordanian energy system with a high share of wind and photovoltaics. Energy 2015;20. http://dx.doi.org/10.1016/j.energy.2015.06.057, http://www.sciencedirect.com.focus.lib.kth.se/science/article/pii/S0360544215008130.

[39] Oikonomou EK, Kilias V, Goumas A, Rigopoulos A, Karakatsani E, Damasiotis M, et al. Renewable energy sources (RES) projects and their barriers on a regional scale: the case study of wind parks in the Dodecanese islands, Greece. Energy Policy 2009;37:4874-83. http://dx.doi.org/10.1016/ j.enpol.2009.06.050.

[40] Papoutsa C, Hadjimitsis DG, Alexakis DD. Coastal water quality near to desalination project in Cyprus using earth observation. p. 81810T-81810T-8. doi:10.1117/12.898361. 2011.

[41] Patlitzianas KD, Christos K. Effective financing for provision of renewable electricity and water supply on Islands. Energy Sustain Dev 2012;16:120-4. http://dx.doi.org/10.1016/j.esd.2011.11.003.

[42] Prodromidis GN, Coutelieris FA. A comparative feasibility study of stand-alone and grid connected RES-based systems in several Greek Islands. Renew Energy 2011;36:1957-63. http://dx.doi.org/10.1016/j.renene.2010.12.021.

[43] Qian H, Zhou Z, Zhang L, Wu F, Zhang Q, Zhang Z. Thermodynamic analysis on the theoretical energy consumption of seawater desalination. Desalination 2013;320:73-9. http://dx.doi.org/10.1016/j.desal.2013.04.006.

[44] Regional Policy - Inforegion. Inforegio: EU regional policy - project examples policy learning database [WWW document]. URLhttp://ec.europa.eu/ regional_policy/projects/practices/details.cfm?pay $=$ GR\&the $=76 \&$ sto $=1437 \&$ region $=$ ALL\&lan $=7 \&$ obj=ALL\&per $=A L L \& d e f L=E N .2012$ (accessed 10.20.14).

[45] RETScreen. RETScreen. 2014.

[46] Samakidis D. Autonomous desalination system using RES: dimensioning and control strategies [WWW Document]. URLhttp://vivliothmmy.ee.auth.gr/192/. 2009 (accessed 11.7.14).

[47] Tarnacki K, Meneses M, Melin T, van Medevoort J, Jansen A. Environmental assessment of desalination processes: reverse osmosis and Memstill $^{\circledR}$. Desalination 2012;296:69-80. http://dx.doi.org/10.1016/ j.desal.2012.04.009.

[48] Voivontas D, Misirlis K, Manoli E, Arampatzis G, Assimacopoulos D. A too for the design of desalination plants powered by renewable energies. Desalination 2001;133:175-98. http://dx.doi.org/10.1016/S0011-9164(01) 00096-0.

[49] Xydis G. Comparison study between a renewable energy supply system and a supergrid for achieving 100\% from renewable energy sources in Islands. Int J Electr Power Energy Syst 2013;46:198-210. http://dx.doi.org/10.1016| j.ijepes.2012.10.046.

[50] Yfantis N. Technical manager of sychem advanced water technologies. 2010

[51] YME. Ministry of infrastructure, transport and networks is: [WWW document]. URLwww.yme.gr/getfile.php?id=2808. 2010.

[52] YPEKA. Legislation framework for RES, 3851/2010 [WWW Document]. URL http://www.aegean-energy.gr/gr/pdf/nomoi/nomos_3851.pdf. 2010.

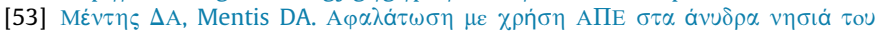
Notiou Atraiou. Desalination units through RES in the arid islands of Greece. 2011. 